\title{
Canine endothelial progenitor cell-lined hybrid vascular graft with nonthrombogenic potential
}

\author{
Hongbing He, MD ${ }^{a, b}$ \\ Toshihiko Shirota, MD ${ }^{a, c}$ \\ Hisataka Yasui, MD, PhD \\ Takehisa Matsuda, $\mathrm{PhD}^{\mathrm{a}}$
}

From the Departments of Biomedical Engineering ${ }^{\mathrm{a}}$ and Cardiac Surgery, ${ }^{\mathrm{b}}$ Graduate School of Medicine, Kyushu University, Fukuoka, and the Department of Bioengineering, ${ }^{c}$ National Cardiovascular Center Research Institute, Osaka, Japan

Supported by the Promotion of Fundamental Studies in Health Science of the Organization for Pharmaceutical Safety and Research (OPSR), grant no. 97-15, and in part by a Grant-in-Aid for Scientific Research (A2-12358017, B2-12470277) from the Ministry of Education, Culture, Sports, Science, and Technology of Japan.

Received for publication March 22, 2002; revisions requested May 16, 2002; revisions received May 29, 2002; accepted for publication July 26, 2002.

Address for reprints: Takehisa Matsuda, MD, Department of Biomedical Engineering, Graduate School of Medicine, Kyushu University, 3-1-1 Maidashi, Higashi-ku grbf, Fukuoka 812-8582, Japan (E-mail: matsuda@med.kyushu-u.ac.jp).

J Thorac Cardiovasc Surg 2003;126:455-64

Copyright (C) 2003 by The American Association for Thoracic Surgery

0022-5223/2003\$30.00+0

doi:10.1016/S0022-5223(02)73264-9
Objective: We sought to fabricate a compliant engineered vascular graft (inner diameter of approximately $4.5 \mathrm{~mm}$ and length of $6 \mathrm{~cm}$ ) lined with endothelial progenitor cells derived from circulating peripheral canine blood and to verify its nonthrombogenicity potential in vivo.

Methods: Autologous circulating endothelial progenitor cells derived from the peripheral veins of 6 adult mongrel dogs were isolated by using a density gradient method. The cells were proliferated in vitro in EGM-2 culture medium, prelined on the luminal surface of in situ-formed collagen type I meshes as an extracellular matrix, and wrapped with a segmented polyurethane thin film with multiple micropores as a compliant scaffold. After canine carotid arteries were bilaterally implanted with these grafts for 1 and 3 months, microscopic observation, histologic staining, and immunochemical staining were performed to evaluate morphogenesis.

Results: After $33.3 \pm 10.5$ days of culture in vitro, $4.2 \pm 1.2 \times 10^{6}$ endothelial progenitor cells were obtained. Eleven of the 12 engineered vascular grafts were patent. The grafts possessed smooth, glistening, and ivory-colored luminal surfaces at the predetermined observation period up to 3 months. The intimal layer was covered with confluent, cobblestone-like monolayered cells that were positively stained with factor VIIIB-related antigen. The thickness of the neoarterial walls was approximately $300 \mu \mathrm{m}$ at 3 months after implantation. A few smooth muscle cells were observed in the medial tissue, and fibroblasts dominated the adventitial tissue.

Conclusion: Circulating endothelial progenitor cells could be a substitute source of endothelial cells for endothelialization on small-diameter-vessel prostheses to ensure nonthrombogenicity.

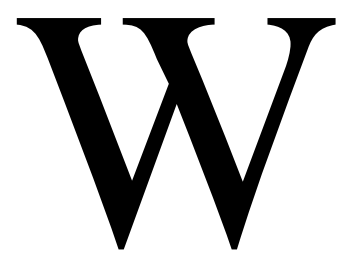

ell-controlled tissue regeneration, healing, and vital function underlying the nonthrombogenic potential of tissue-engineered small-diameter vascular grafts can be achieved with combinations of a proper selection of key element materials, a fabrication process technology of grafts, and a proper cell-seeding technique and use of an appropriate source of vascular cell types. It has been verified by many research groups that an autologous endothelial cell (EC)-lined graft has proved antithrombogenicity. However, despite the experimentally proved nonthrombogenicity of endothelialized hybrid grafts, only a limited clinical application of such grafts has been reported, although Deutsch and colleagues ${ }^{1}$ have been continuously implanting endothelialized grafts under well-controlled clinical criteria using a defined technique. Although significant advancement in vascular tissue engineering has been made with ECs, harvesting ECs from a patient remains a problem of great concern.

On the other hand, recent studies evidenced that mature ECs and immature endothelial-like cells float in circulating peripheral blood..$^{2-5}$ Mature ECs are derived 


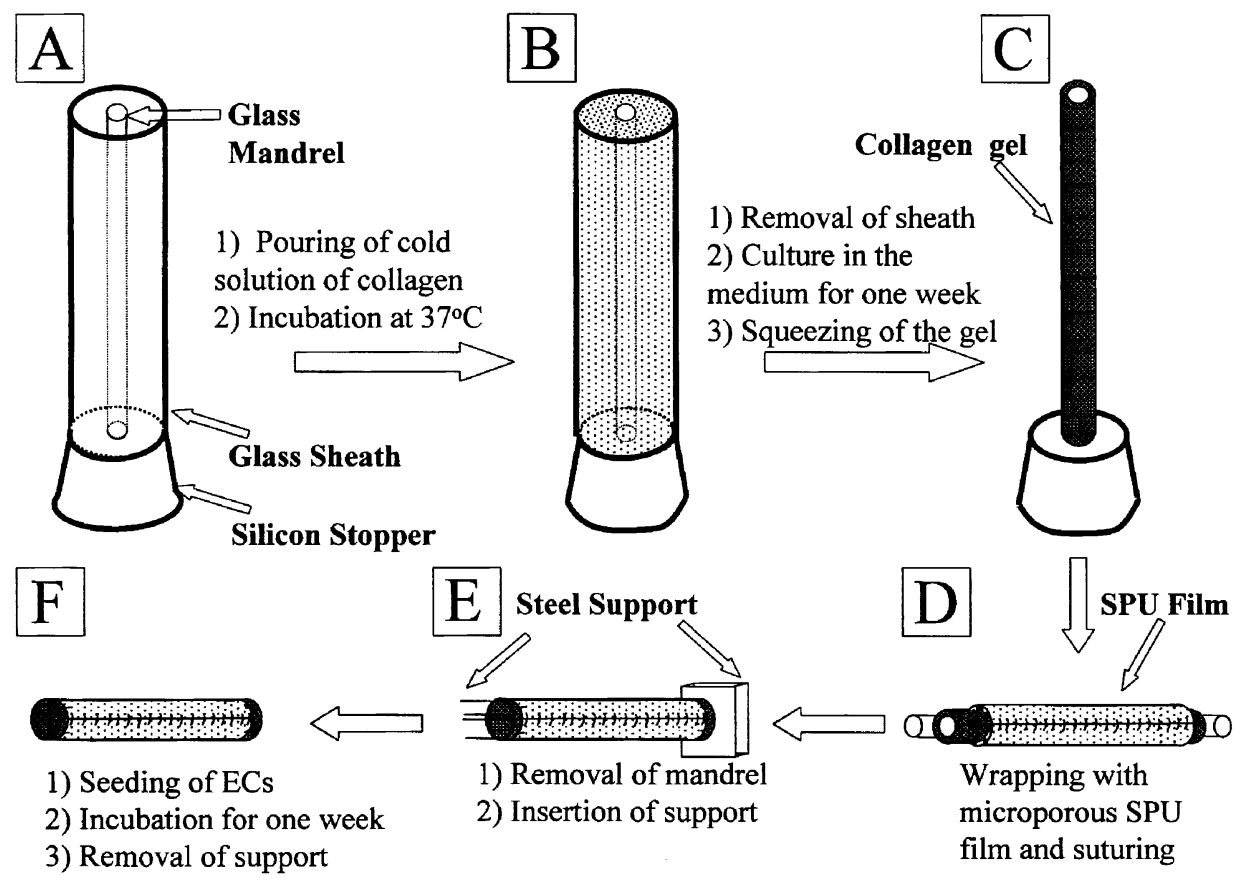

Figure 1. Schematic of fabrication processes for the artificial vascular graft that is lined with an in situ-formed type I collagen mesh as the matrix and wrapped with the SPU as the scaffold.

from those that fall out from the vascular wall (fall-out ECs). The possibility of the existence of fall-out ECs has been discussed over the years, and the fall-out hypothesis recently has been verified experimentally. ${ }^{6}$ Endothelial progenitor cells (EPCs), which fall out from the bone marrow, ${ }^{3,4,7}$ are expected to have much higher proliferative potential than mature fall-out ECs. ${ }^{4}$ It is anticipated that when EPCs are harvested from peripheral blood and effectively proliferate, they serve as a very promising alternative source of lining for cells. This eliminates the need for surgical removal of the veins from which ECs are usually harvested for tissue-engineered vascular grafts. Recently, Kaushal and coworkers ${ }^{8}$ reported that ovine EPC-seeded, decellularized porcine iliac vessels have been remodeled to provide a functional vessel on implantation and inherent functional properties, especially nitric oxide (NO) production in response to physiologic stimuli, suggesting that EPCs are being differentiated to mature ECs with implantation time and strongly implying that the EPC is an alternative source of nonthrombogenic cell lining.

In this study EPCs were harvested from canine peripheral blood and cultured. A compliant graft, which was assembled with in situ-prepared collagen fiber meshes and a microporous segmented polyurethane (SPU) tubular film, was seeded with EPCs. The preliminary in vivo implantation study was conducted up to 3 months.

\section{Materials and Methods}

\section{Harvesting and Culturing}

The investigations were performed according to the "Principles of Laboratory Animal Care" (formed by the National Society for Medical Research) and the "Guide for the Care and Use of Laboratory Animals" (National Institutes of Health publication no. 56-23, revised 1985). Peripheral blood (15 mL/sample) was collected from 6 adult male mongrel dogs (weight, $27.5 \pm 3.1 \mathrm{~kg}$ ) by means of venipuncture, placed in 50-mL polypropylene centrifuge tubes (IWAKI; Asahi Techno Glass, Tokyo, Japan), and anticoagulated with heparin sodium (final concentration, $200 \mathrm{U} / \mathrm{mL}$; Novo Corp, Tokyo, Japan). The anticoagulated blood was diluted 1:2 with Hanks solution (Life Technologies Inc, Rockville, Md) containing $1 \mathrm{mmol} / \mathrm{L}$ ethylenediamine tetraacetic acid and $0.5 \%$ bovine serum albumin.

Mononuclear cells were isolated from the blood sample by using a density gradient method with Histopaque-1077 (Sigma Chemical Co, St Louis, Mo) according to the manufacturer's instructions. Cells obtained from the plasma-Histopaque-1077 interface were washed 3 times by means of centrifugation at $250 \mathrm{~g}$ for 10 minutes with MCDB 131 medium (Lite Technologies Inc), containing $5 \mathrm{U} / \mathrm{mL}$ heparin sodium. The cells resuspended in EGM-2 culture medium (Clonetics Inc, San Diego, Calif) were inoculated into a culture dish precoated with type I collagen (IWAKI, Asahi Techno Glass) and cultured in EGM-2 in a humidified atmosphere of $5 \% \mathrm{CO}_{2}$ at $37^{\circ} \mathrm{C}$. The culture medium was freshened twice a week. When the primary cells reached approximately two thirds of the growth area, the cells were subcultured with $0.01 \%$ trypsin (Life Technologies Inc) phosphate-buffered 


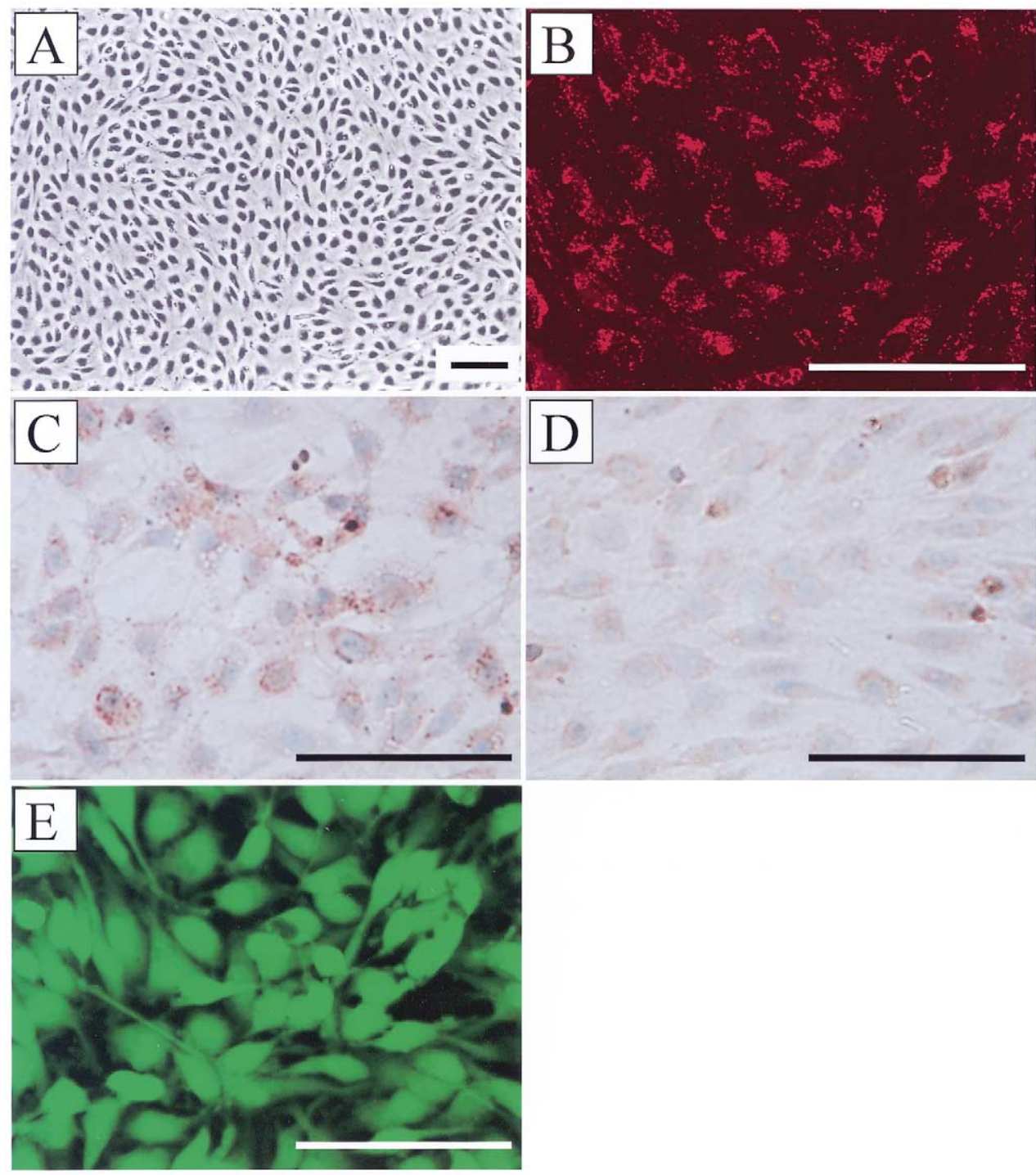

Figure 2. Blood-derived circulating EPCs in subculture: $A$, phase-contrast microscopy (original magnification $100 \times$ ); $B$, positive uptake of fluorescence-labeled acetylated low-density lipoprotein (confocal scanning microscopy; original magnification $400 \times$ ); $C$, positive immunochemical staining of factor VIII-related antigen (light microscopy; original magnification $400 \times$ ); $D$, positive immunochemical staining of Flk-1 (light microscopy; original magnification $400 \times$ ); $E$, intracellular NO production proved by means of intracellular staining with an NO-specific indicator, DAF-2DA. Scale bars $=100 \mu \mathrm{m}$.

saline solution and inoculated into a nonpretreated polystyrene culture dish (IWAKI, Asahi Techno Glass) with a split ratio of 1:4 to 6. The immunohistologic staining of the rat monoclonal antifactor VIII-related antigen (Dako Corp, Glostrup, Denmark) and mouse monoclonal anti-human Flk-1 (Santa Cruz Biotechnology Inc, Santa Cruz, Calif), as well as the uptake of fluorescencelabeled acetylated low-density lipoprotein (DiI-acetylated-LDL; Biomedical Technologies Inc, Stought, Mass) were performed to identify the subcultured cells. Diamino-fluorescein-2 diacetate (DAF-2DA; Daiichi Pure Chemicals Co, Ltd, Tokyo, Japan), which is a membrane-permeable, intracellular, NO-specific green fluorescence indicator, was used to detect NO expression. ${ }^{9}$ EPCs immersed in serum-free M199 containing $5 \mu \mathrm{mol} / \mathrm{L}$ DAF-2DA for 60 minutes at $37^{\circ} \mathrm{C}$ were fixed and examined with a confocal laser scanning microscope (Radiance 2000; Bio-Rad Laboratories Inc, Hercules, Calif).

\section{Cell Growth Curve}

The number of subcultured cells in the culture dish was determined by using the method described by Zilla and associates. ${ }^{10}$ Briefly, by using a convert microscope, photographs were taken in 10 randomized areas at a magnification of $200 \times$ with instant film (Polaroid 667, Cambridge, Mass). The number of cells in each 


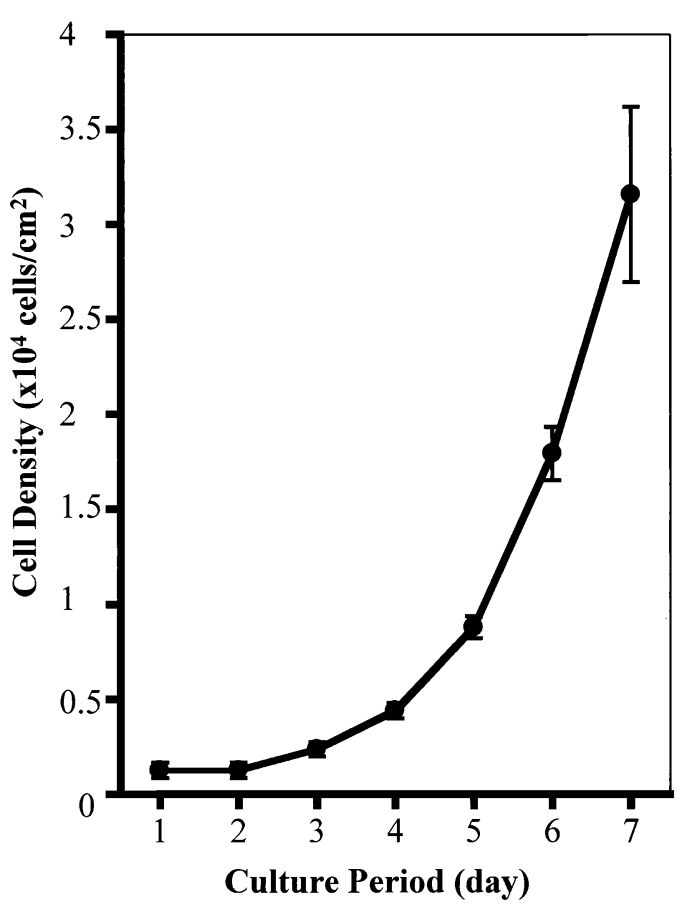

Figure 3. Growth curve of the circulating EPCs in subculture. Each result is expressed as the mean \pm SD. The PDT in the exponential stage was 23 to 29 hours.

photograph was counted. The cell density was calculated from the average number of cells in the 10 photographs. The population doubling time (PDT) was determined on the basis of the growth curve (from the first day after subculture to the seventh day, $n=3$ ).

\section{Fabrication of the Artificial Vascular Graft}

The procedure followed for fabrication of the compliant artificial vascular graft was our previously reported method. ${ }^{11}$ Briefly, a cold mixture of $8 \mathrm{~mL}$ of M199 (Life Technologies Inc) culture medium and $8 \mathrm{~mL}$ of acid-solubilized bovine dermal type I collagen solution (0.3\%, CELLGEN; Koken Corp, Tokyo, Japan) was used to fill the space between the sheath (inner diameter of $15 \mathrm{~mm}$ ) and mandrel (outer diameter of $5 \mathrm{~mm}$ ) of a tubular glass mold, as shown in Figure 1. After subsequent thermal gelation at $37^{\circ} \mathrm{C}$ for 30 to 60 minutes, the sheath was removed. The resultant collagen gel was allowed to stand in the medium for an additional week. The collagen gel around the glass mandrel was squeezed to expel water; wrapped with a 6-cm-long SPU (thickness of $100 \mu \mathrm{m}$; Shidame Co, Ltd, Tokyo, Japan) in which the pore-to-pore distance and the pore size were $1 \mathrm{~mm}$ and $100 \mu \mathrm{m}$, respectively; and then sutured by using the surgical continuous suture technique. Details of the in-house preparation of micropores by using the excimer laser ablation technique were described in our previous work. ${ }^{12}$ The collagen gel was designed $3 \mathrm{~mm}$ longer than the SPU film wrapping at both ends to prevent the formation of a false aneurysm in the anastomotic sites after interposition. Protruding parts were everted on both ends of the graft to encapsulate the edges of the wrapping and were fixed with 4 sutures circumferentially. The protocol for prelining the inner surface of the vascular graft with EPCs was described in detail in our previous article. ${ }^{13}$ Briefly, after $2 \mathrm{~mL}$ of EPC-containing M199 solution $\left(1.0 \times 10^{6}\right.$ cells $/ \mathrm{mL}$ ) was poured into the lumen of the tissue, the graft was placed horizontally and incubated at $37^{\circ} \mathrm{C}$ for 20 minutes. Then the graft was rotated $90^{\circ}$, and additional EPC-containing M199 solution was poured into the lumen of the graft. This process was repeated 4 times to achieve confluent density of ECs on the luminal surface of the graft. After 2 days of incubation in M199 supplemented with $20 \%$ fetal bovine serum, an EPC-seeded graft was obtained. An intraluminal mechanical support with 6 stainless steel wires, which was described in our previous article, ${ }^{13}$ was used when EPCs were seeded. The support was removed before implantation.

\section{Graft Implantation and Retrieval}

General anesthesia was induced by means of injection of intramuscular ketamine (Ketaral 50, 15 mg/kg; Sankyo Co, Ltd, Tokyo, Japan) and intravenous pentobarbital (Nembutal, $19 \mathrm{mg} / \mathrm{kg}$; Dainippon Pharmaceutical Co, Ltd, Osaka, Japan) and maintained by means of intermittent injection of pentobarbital. Bilateral paratracheal incisions were made along the trachea, and both common carotid arteries were dissected, which yielded a segment approximately $10 \mathrm{~cm}$ in length. The end-to-end interposition of the prepared artificial vascular graft was performed by running 6-0 polyprolene sutures into bilateral common carotid arteries of the same dog from which the cells were isolated. Neither anticoagulant nor antiplatelet agents were administered, except for the intraoperative heparin $(100 \mathrm{U} / \mathrm{kg})$ injected intravenously. The implantation observation period was predetermined to occur at 1 and 3 months. Graft patency was evaluated with manual palpation of the pulse and direct observation of blood flow through the grafts at the time of death. The graft, together with approximately $1-$ to $2-\mathrm{cm}$ native arteries at both ends, was fixed at $150 \mathrm{~mm} \mathrm{Hg}$ of pressure for 2 hours with $300 \mathrm{~mL}$ of fixative after flushing with $500 \mathrm{~mL}$ of phosphate-buffered saline solution containing $100 \mathrm{U} / \mathrm{mL}$ heparin for approximately 30 minutes to 1 hour. Then the graft was longitudinally opened, photographed, and subjected to further evaluation.

\section{Scanning Electron Microscopic Examination}

After postfixation in 1\% osmium tetroxide, freeze-drying, and subsequent coating by sputtering with platinum, the luminal surfaces of the samples were observed with a scanning electron microscope (S-4000; Hitachi Corp, Tokyo, Japan).

\section{Histologic Examination}

Longitudinally prepared histologic sections were subjected to histologic staining by using the following stains. First, hematoxylinand-eosin stain was used for general evaluation. The thickness of the neoarterial wall, defined as the thickness of the tissue between the EPC monolayer and the inner surface of the SPU film, was measured from the distal anastomostic site to the midportion of the graft interval of $0.5 \mathrm{~cm}$. Five metric points for each graft were projected with the aid of an image processor (original magnification $100 \times$ ). Second, Masson trichrome stain was used for collagen. Third, Alcian blue stain was used for proteoglycans. A monoclonal mouse antibody against an anti-factor VIII-related antigen (for EPCs), anti-vimentin (for fibroblasts), and anti-smooth muscle 

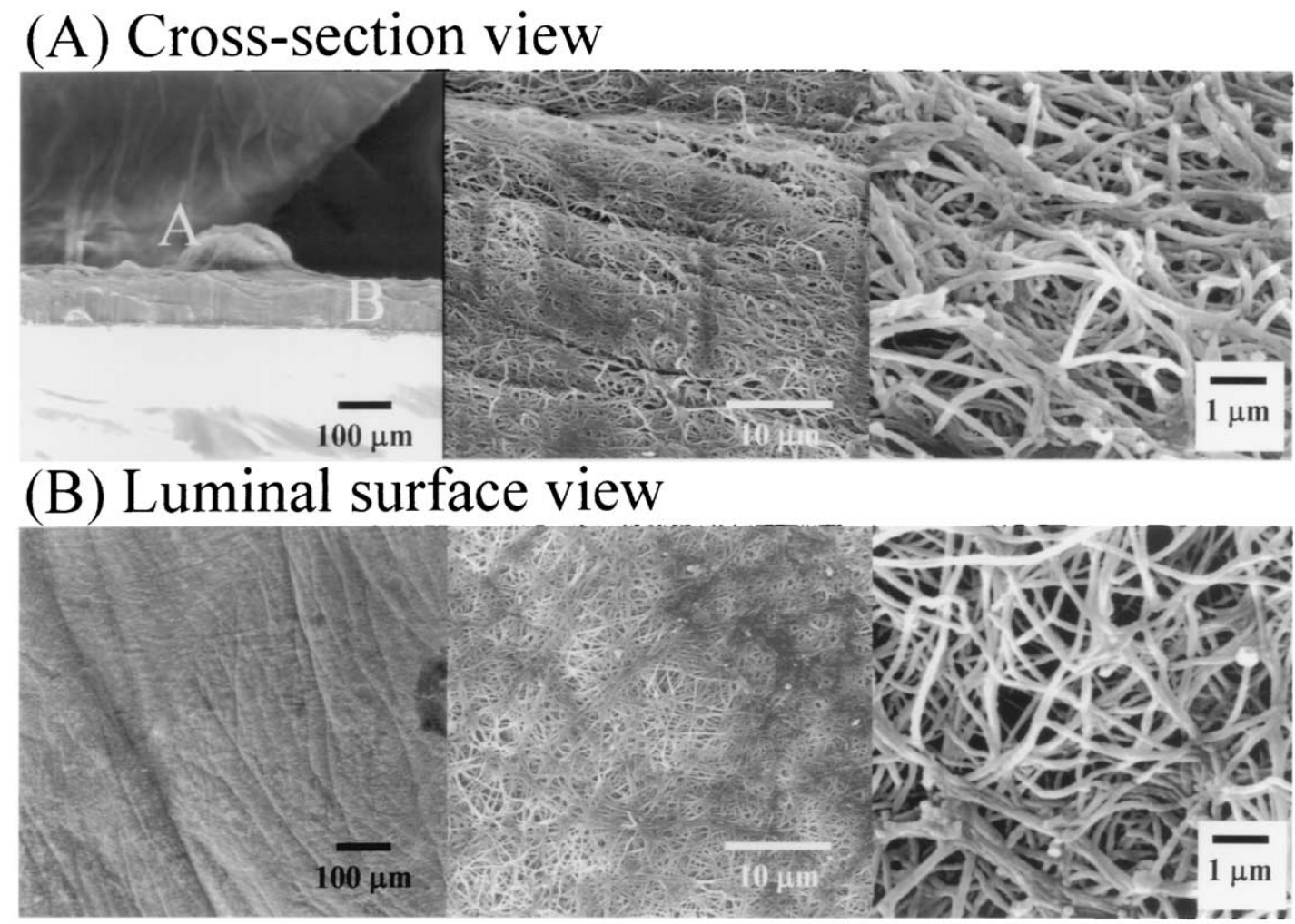

Figure 4. Scanning micrograph of cross-sectional $(A)$ and luminal $(B)$ views of in situ-formed collagen mesh at different magnifications (magnification is enlarged from left to right). Note that $A$ in the cross-sectional view with the lowest magnification denotes the dense collagen meshes formed in micropores when squeezed, and $B$ denotes a dense collagen mesh layer.

$\alpha$-actin (for smooth muscle cells), all of which were purchased from Dako Corp, were used as primary antibodies, respectively, and the biotin-avidin-peroxidase-labeled rat anti-rabbit IgG served as the secondary antibody to identify the cell types in the neoarterial wall of the grafts.

\section{Results}

Mononuclear cells in peripheral blood isolated by means of the centrifugal gradient density technique were cultured in collagen-coated dishes. The majority of isolated mononuclear cells died within 2 to 3 weeks of culture. Colonies of proliferating cells appeared at approximately 10 days, and the primary culture of the surviving cells $(n=6)$ was continued for $17.3 \pm 6.5$ days before subculture. The harvest rate of EPCs was approximately $15 \%$ (blood volume per sample, $15 \mathrm{~mL}$; total number of samples, 40; number of generations of colony, 12; number of proliferative EPCs, 6). Figure 2 demonstrates that the subcultured cells exhibited a cobblestone-like morphology (Fig 2, A), positive uptake of fluorescence-labeled acetylated low-density lipoprotein (Fig $2, B)$, and positive staining of the factor VIII-related antigen (Fig 2,C) and Flk-1 (Fig 2, D). These cells also produced NO intracellularly, which was proved by means of intracel- lular staining with an NO-specific indicator, DAF-2DA (Fig 2, E). Our experiments showed that approximately $4.2 \pm$ $1.2 \times 10^{6}$ EPCs were regularly obtained after $16 \pm 4$ days at 1 to 2 passages of subcultures. The PDT during the exponential stage of cell proliferation, which started from 2 to 3 days after subculture and was semiquantatively determined, ranged from 23 to 29 hours, and the average PDT calculated was $24.2 \pm 2.5$ hours (Figure 3 ).

The hybrid vascular graft, which is composed of a confluent EPC monolayer, dense collagen fiber mesh layer, and microporous thin SPU film, was prepared according to the schematic shown in Figure 1. Briefly, after a collagen gel was formed in the interspace between a mold consisting of an inner glass mandrel and an outer glass sheath, a microporous SPU film was wrapped and squeezed tightly to expel water out to form dense collagenous fiber meshes, as shown in Figure 4. Collagen meshes completely covered the luminal surface of an SPU tube in which micropores were filled with collagen meshes. After tight wrapping with the microporous SPU film and suturing, the glass mandrel was carefully removed to leave a collagen mesh-lined SPU tube. EPCs were seeded on the luminal surface of the graft and 


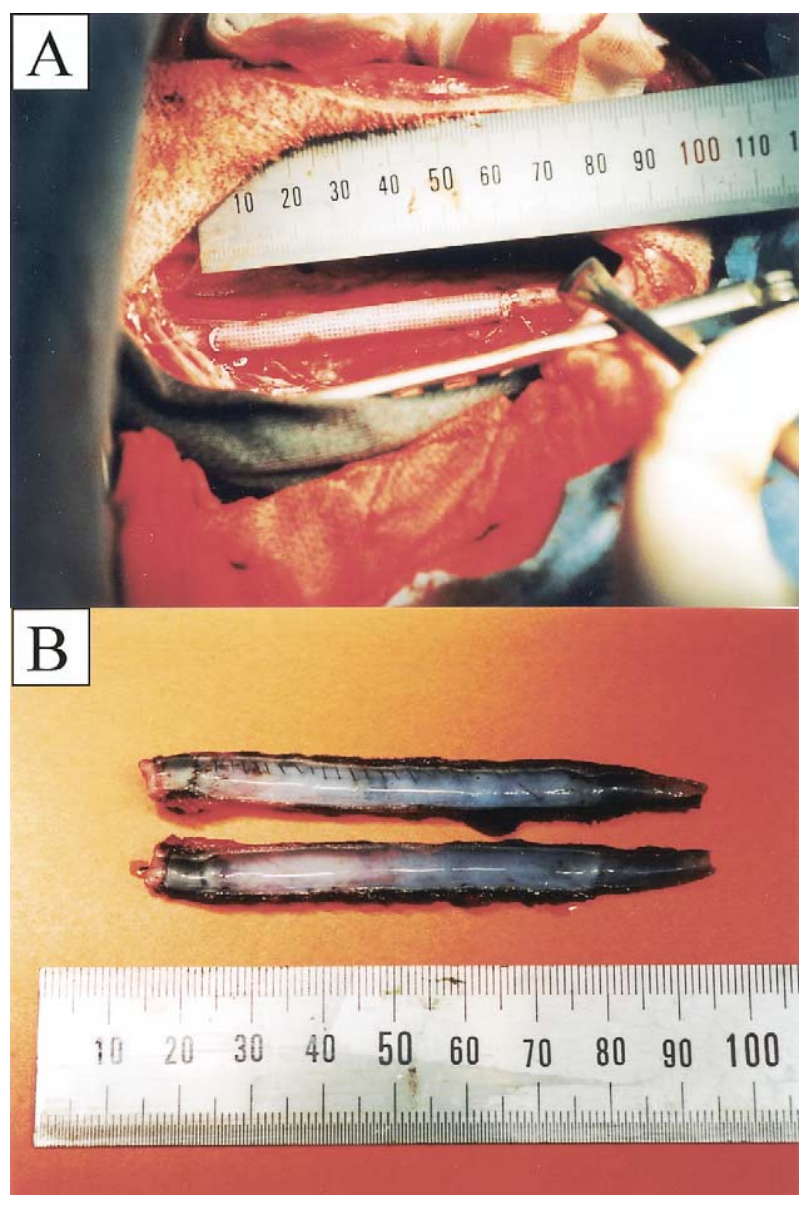

Figure 5. Macroscopic examination of EPC-seeded vascular grafts: $A$, as implanted; $B$, the grafts had a smooth, glistening, and ivory-colored luminal surface 3 months after implantation.

\section{TABLE 1. Patency versus implantation period}

\begin{tabular}{cc}
\hline Implantation period $(\mathbf{m o})$ & No. of implanted grafts \\
\hline 1 & $6(1)^{*}$ \\
3 & $6(0)$
\end{tabular}

*Number in parentheses represents the number of dilated or occluded grafts.

further cultured for 1 week. The graft (dimensions of approximately $4.5 \mathrm{~mm}$ in diameter and $6 \mathrm{~cm}$ in length) was connected to the carotid arteries of a dog from which peripheral blood was withdrawn (Figure 5, A). There was neither dilation along the graft nor stricture at either anastomostic site at implantation. The projected implantation period was scheduled to occur at 1 and 3 months. Eleven of 12 implanted grafts were completely patent. The smooth, glistering, ivory-colored luminal surfaces, which are free of thrombus, were observed for completely patent grafts at 3 months after implantation (Fig 5, B). One graft at 1 month after implantation was dilated and partially occluded by the thrombus, which might be due to loosening of the wrapping sutures along the graft. The overall results of the implanted grafts are summarized in Table 1.

Scanning electron microscopic observation showed that the luminal surfaces of the grafts at 3 months after implantation were covered with a confluent monolayer of cobblestone-like cells oriented parallel to the direction of arterial flow (Figure 6, $A$ and $B$ ). Immunohistologically, monolayered cells on the luminal surface of the graft were positive for the factor VIII-related antigen, as shown in Figure 7, A. The ingrowth of the surrounding connective tissue through the pores of the wrapping material was distinct (Figure 7, $B)$ : cells strongly stained with anti-vimentin, probably identified as fibroblasts, invaded the pore in up to two thirds of the neoarterial tissue and the thin layer in the luminal region. Cells (defined as smooth muscle cells) positively stained with smooth muscle cell-specific $\alpha$-actin, were observed, with accumulation in the subtissue beneath the luminal surface and distribution in the middle part of the neoarterial tissue (Figure 7,C). Figure 8 shows a typical morphogenetic feature of the tissue stained with hematoxylin and eosin (cells), Masson trichrome (collagen), and Alcian blue (proteoglycan), indicating that tissue regeneration proceeded well. The neoarterial walls have a thickness of less than $200 \mu \mathrm{m}$ at 1 month after implantation and approximately $300 \mu \mathrm{m}$ at 3 months after implantation (Figure 9). For both cases, there is little distance dependency of neoarterial tissue formation (from the anastomotic site).

\section{Discussion}

Although extensive efforts have been made to develop a vital, functioning, small-diameter artificial graft (inner diameter of $<5 \mathrm{~mm}$ ), none have been realized clinically. On the other hand, EC transplantation onto a synthetic artificial graft by using either seeding or sodding techniques has exhibited proved nonthrombogenic potential once a fully endothelial monolayer that can withstand high pressureloaded arterial circulatory stress is formed on the luminal surface of the artificial graft. ${ }^{1}$ Early successes achieving long-term patency of EC-lined small-diameter grafts in animal studies have not been followed by extensive use of this technology in human subjects, except for by Zilla's group, who have been extensively implanting EC-seeded grafts under well-defined clinical criteria and surgical procedures and reported a more than 9-year follow-up study. The major reasons for limited clinical realization must be the limited number of ECs that can be obtained from a segment of autologous vein, as well as questions concerning the removal of viable vein segments from patients with vascular diseases. 


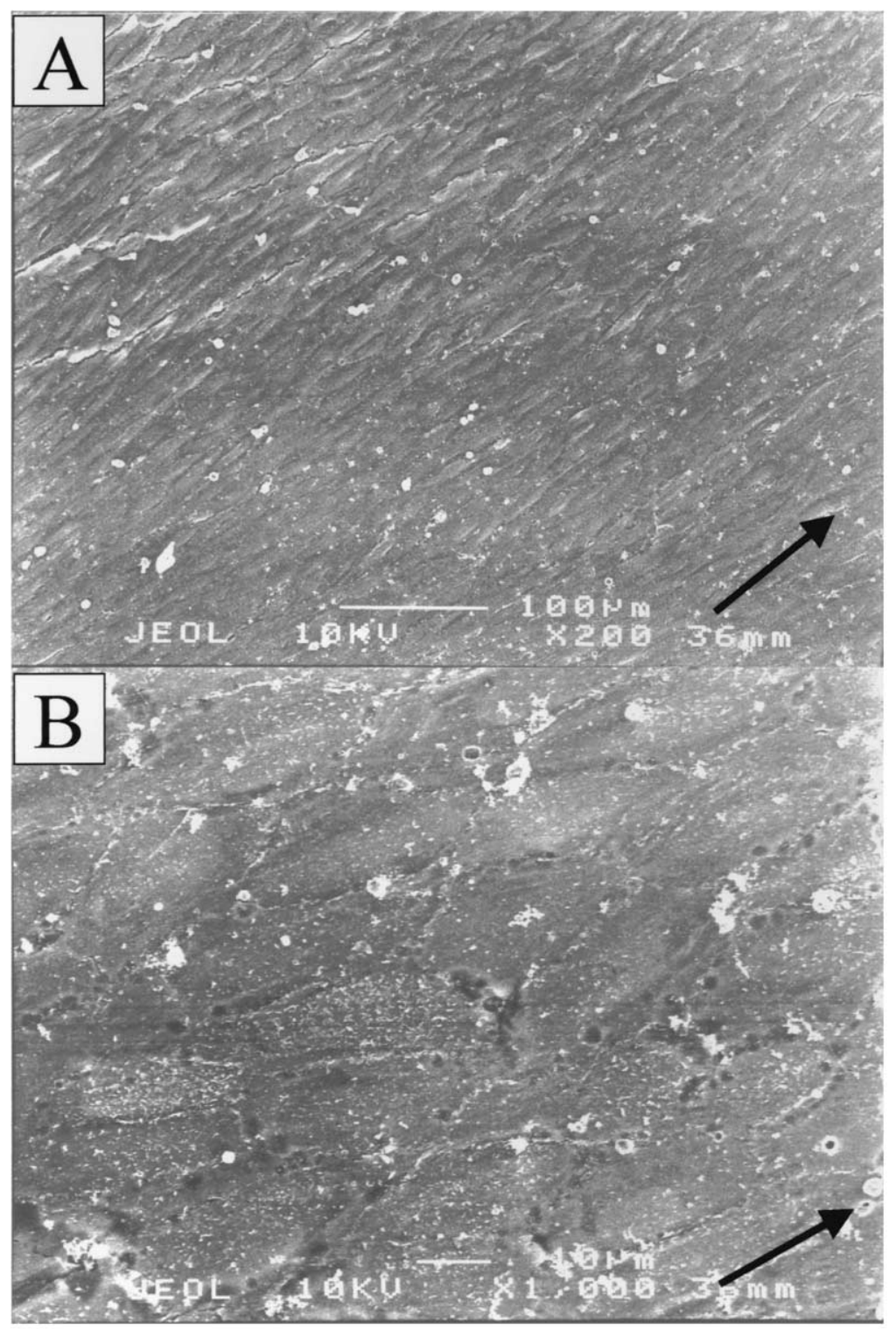

Figure 6. Scanning electron micrographic examination of the luminal surface of the graft 3 months after implantation. The intima was covered with a confluent endothelial monolayer oriented parallel to the direction of arterial blood flow. (Original magnification: $A, 100 \times ; B, 1000 \times$.) Arrows indicate the direction of arterial blood flow.

\begin{abstract}
Alternative sources of autologous ECs are omental fat ${ }^{14}$ or adipose tissues. ${ }^{15}$ ECs from omental microvascularized fat on an artificial graft have experimentally contributed to endothelialization. However, it has been suggested that microvascular ECs from omental tissue are not of endothelial origin. ${ }^{16}$ Sodding of fragmented vessel tissues has been clinically used in Japan. On implantation, in situ cell sorting resulted in the formation of EC lining on subvascular tissue with implantation time. ${ }^{17}$ However, this method might not be applicable to a small-diameter graft because massive thrombus is formed at a very early phase of implantation. ${ }^{18}$
\end{abstract}

Recent studies have shown that mature fall-out ECs detached from the vascular wall and bone marrow-derived EPCs are circulating in the peripheral bloodstream..$^{2-5} \mathrm{~A}$ very small amount of bone marrow-derived EPCs circulating in blood, which are differentiated from $\mathrm{CD} 34^{+}$cells, form endothelial colonies. ${ }^{3-5,19}$ These cells uptake acetylated low-density lipoprotein, produce NO by means of vascular endothelial growth factor stimulation, and express von Willebrand factor, vascular endothelial cadherin, platelet endothelial cell adhesion molecule 1, vascular endothelial growth factor receptor 2 (Flk-1), and Tie-2 receptor. ${ }^{2,3,20}$ 


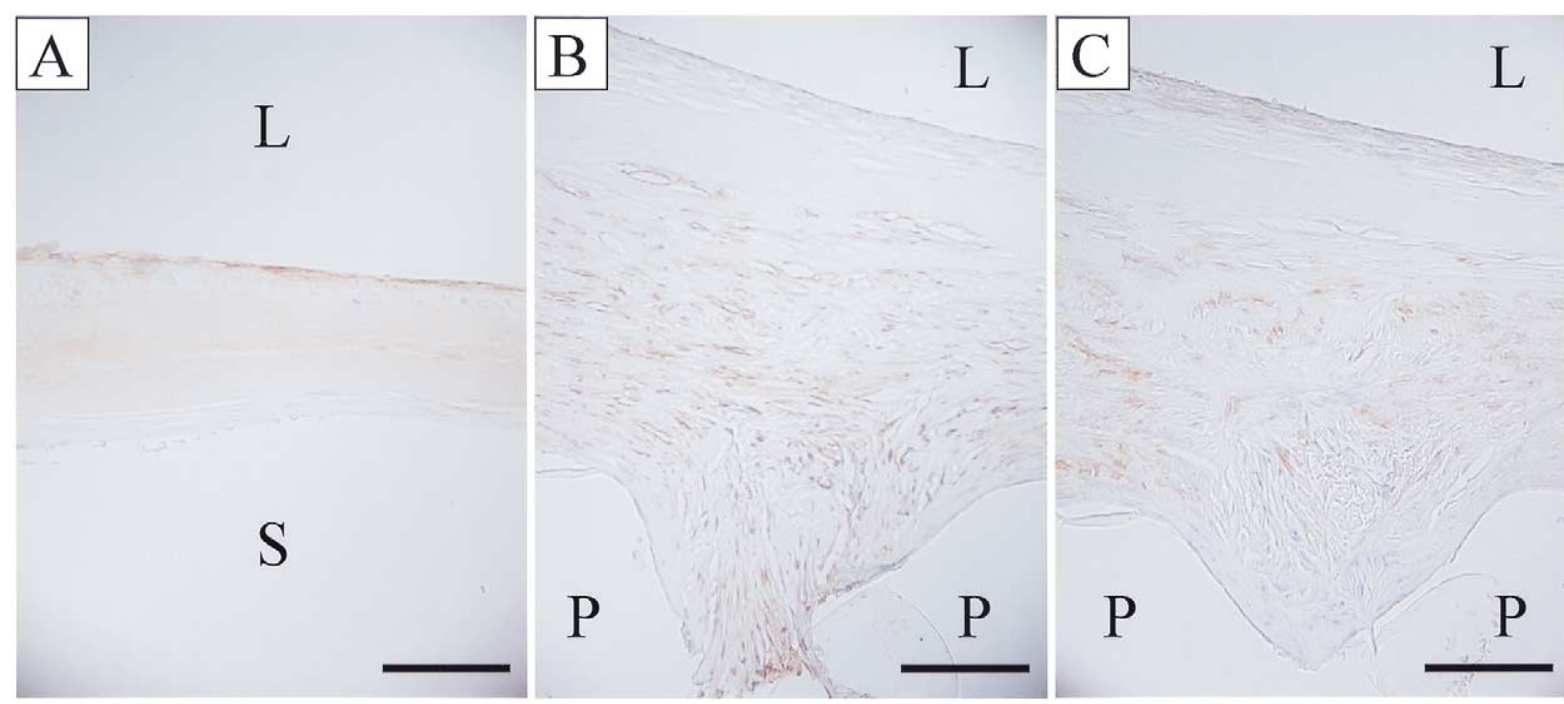

Figure 7. Immunochemical staining of the neoarterial wall of EPC-seeded vascular grafts 3 months after implantation: $A$, monoclonal antibody against factor VIII-related antigen (original magnification $200 \times$ ); $B$, monoclonal antibody against vimentin (original magnification 200X); $C$, monoclonal antibody against smooth muscle $\alpha$-actin (original magnification $200 \times$ ). L, Luminal surface; $S$, SPU-contacting surface; $P$, wrapped polyurethane. Scale bars $=100 \mu \mathrm{m}$.

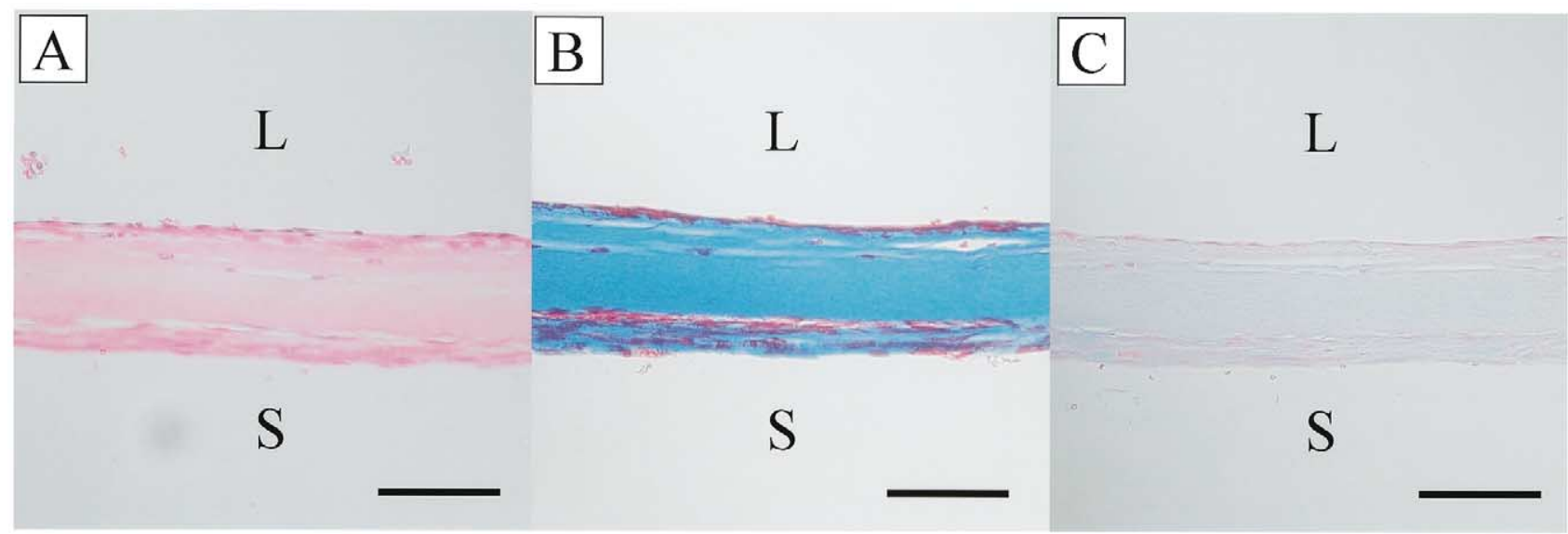

Figure 8. Histologic examination of the neoarterial wall of EPC-seeded vascular grafts 3 months after implantation (original magnification $200 \times$ ): $A$, hematoxylin and eosin staining; $B$, Masson trichrome staining; $C$, Alcian blue staining. $L$, Luminal surface; $S$, SPU-contacting surface. Scale bars $=100 \mu \mathrm{m}$.

Before the existence of EPCs in circulating blood was scientifically defined, several articles reported that implanted artificial devices were endothelialized for a long period in vivo. The contribution of such ECs or EPCs to endothelialization on impervious artificial grafts and ventricular assist devices, both of which totally prevent transinterstitial tissue ingrowth, was observed in canine and sheep models, respectively. Shi and coworkers ${ }^{6}$ reported that scattered islands of endothelial-like cells and $\alpha$-actin-positive smooth muscle cells were found beneath some of the endo- thelial islands on the artificial graft. In addition, Frazier and associates $^{21}$ reported neointima that formed on the surface of left ventricular assist devices is colonized by $\mathrm{CD} 34^{+}$ cells.

Our separate study with human EPCs revealed that antiplatelet activity, as determined quantitatively on the basis of the production rate of endothelial-type NO synthase and prostacyclin, and fibrinolytic activity, as determined on the basis of the production rate of the tissue plasminogen activator, were almost one third to one half of the former 


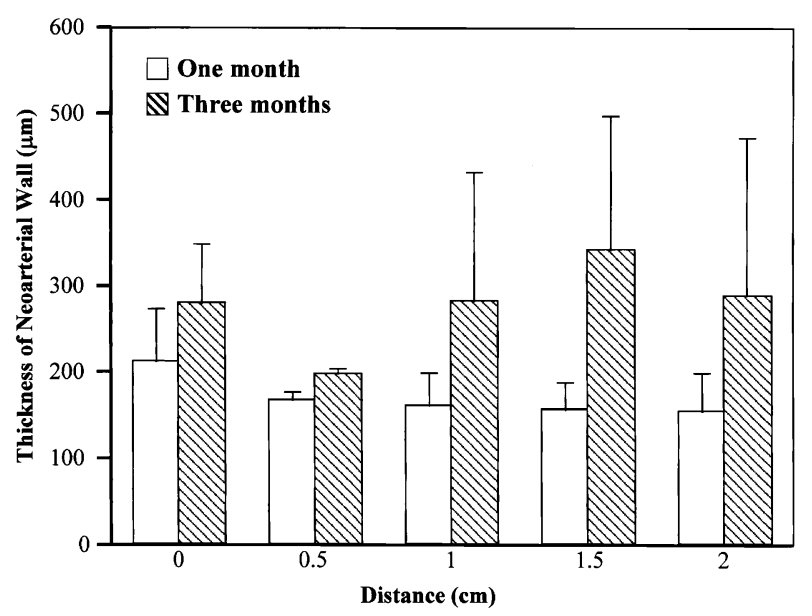

Figure 9. Thickness of neoarterial wall as a function of distance from distal anastomotic site 1 and 3 months after implantation. Each result is expressed as the mean \pm SD.

activity of human ECs and almost equivalent for the latter. ${ }^{22}$ Therefore human EPCs might have nonthrombogenicity close to that of ECs.

In this study canine EPCs harvested from circulating peripheral blood and cultured according to a method similar to that previously reported ${ }^{22}$ were obtained at a harvesting rate of approximately $15 \%$ on single (15 mL of blood) or multiple sampling. (Note that this rate is very high compared with approximately $18 \%$ for human EPCs from 100 $\mathrm{mL}$ of blood, as shown in our experiment. ${ }^{22}$ ) The uptake of low-density lipoprotein, the expression of factor VIII and Flk-1, and the production of intracellular NO showed that EPCs have the characteristic features of ECs. The patency rate of EPC-based hybrid grafts was almost the same as those of EC-based hybrid grafts, both of which use the same scaffold (microporous SPU tube) and extracellular matrix (collagen meshes). ${ }^{23}$ This pulsatile stress-responsive elastomeric tubular scaffold was found to have compliance close to that of canine native carotid arteries, which was investigated in detail in our previous articles.

In situ-formed collagen meshes as a cell-adhering matrix penetrated into and filled micropores of the microporous SPU wall scaffold, thus enabling exertion of the adhesion strength of cell-matrix complexes on the SPU film, which withstands continuously loaded pulsatile stress-inducing hydrodynamic shear stress and mechanical wall distension. The transmural or transinterstitial tissue ingrowth from perigraft tissues through micropores was accompanied with vimentin-positive cells (probably fibroblasts). At 3 months after implantation, smooth muscle cells $(\alpha$-actin positive cells) were accumulated beneath the luminal surface and scattered distributed in the medial layer. Although we have not yet determined quantitatively the nonthrombogenic potentials of implanted EPCs, EPCs are expected to differen- tiate into mature ECs as the implantation period proceeds. This means that EPCs existing in circulating peripheral blood can be an alternative cell source for vascular tissueengineered grafts. In fact, recent clinical studies have shown that the infusion of the mononuclear cell fraction or CD34 $4^{+}$ cells, both of which contain EPCs, into ischemic tissues in legs markedly improved the blood circulation in peripheral regions caused by vasculogenesis. ${ }^{24}$ On the other hand, a recent study of ovine EPC-seeded decellularized porcine iliac vessels exhibited high patency, as well as contractile activity and NO-mediated vascular relaxation, similar to that of native arteries. ${ }^{8}$ Thus on the basis of these preceding studies, EPC-based engineered grafts are clinically promising. Because isolation of EPCs and their mass proliferation is a critical task for such an engineered graft, harvesting from a patient's bone marrow by mobilizing with the aid of colony-stimulating factor and isolation and clonal proliferation of EPCs is more suited than those from peripheral blood.

$\mathrm{Dr} \mathrm{He}$ is on leave of absence from the Zhujiang Hospital affiliated to the First Military Medical University of PLA, P.R. China.

\section{References}

1. Deutsch M, Meinhart J, Fischlein T, Preiss P, Zilla P. Clinical autologous in vitro endothelialization of infrainguinal ePTFE grafts in 100 patients: a 9-year experience. Surgery. 1999;126:847-55.

2. Asahara T, Murohara T, Sullivan A, Silver M, van der Zee R, Li T, et al. Isolation of putative progenitor endothelial cells for angiogenesis. Science. 1997;275:964-7.

3. Shi Q, Rafii S, Wu MH, Wijelath ES, Yu C, Ishida A, et al. Evidence for circulating bone marrow-derived endothelial cells. Blood. 1998; 92:362-7.

4. Lin Y, Weisdorf DJ, Solovey A, Hebbel RP. Origins of circulating endothelial cells and endothelial outgrowth from blood. J Clin Invest. 2000;105:71-7.

5. Peichev M, Naiyer AJ, Pereira D, Zhu Z, Lane WJ, Williams M, et al. Expression of VEGFR-2 and AC133 by circulating human CD34(+) cells identifies a population of functional endothelial precursors. Blood. 2000;95:952-8.

6. Shi Q, Wu MH, Hayashida N, Wechezak AR, Clowes AW, Sauvage LR. Proof of fallout endothelialization of impervious Dacron grafts in the aorta and inferior vena cava of the dog. J Vasc Surg. 1994;20:54657

7. Shi Q, Wu MH, Fujita Y, Ishida A, Wijelath ES, Hammond WP, et al. Genetic tracing of arterial graft flow surface endothelialization in allogeneic marrow transplanted dogs. Cardiovasc Surg. 1999;7:98105.

8. Kaushal S, Amiel GE, Guleserian KJ, Shapira OM, Perry T, Sutherland FW, et al. Functional small-diameter neovessels created using endothelial progenitor cells expanded ex vivo. Nat Med. 2001;7:103540 .

9. Kojima H, Nakatsubo N, Kikuchi K, Kawahara S, Kirino Y, Nagoshi $\mathrm{H}$, et al. Detection and imaging of nitric oxide with novel fluorescent indicators: diaminofluoresceins. Anal Chem. 1998;70:2446-53.

10. Zilla P, Fasol R, Dudeck U, Siedler S, Preiss P, Fischlein T, et al. In situ cannulation, microgrid follow-up and low-density plating provide first passage endothelial cell mass cultures for in vitro lining. $J$ Vasc Surg. 1990;12:180-9.

11. He HB, Matsuda T. Newly designed compliant hierarchic hybrid vascular graft wrapped with microporous elastomeric film (II): morphogenesis and compliance change upon implantation. Cell Transplant. 2002;11:75-87. 
12. Doi K, Nakayama Y, Matsuda T. Novel compliant and tissue-permeable microporous polyurethane vascular prosthesis fabricated by an excimer laser ablation technique. J Biomed Mater Res. 1996;31:27-33.

13. Kobashi T, Matsuda T. Branched hybrid vessel: in vitro loaded hydrodynamic forces influence the tissue architecture. Cell Transplant. 2000;9:93-105.

14. Jarrell BE, Williams SK, Stokes G, Hubbard FA, Carabasi RA, Koolpe $\mathrm{E}$, et al. Use of freshly isolated capillary endothelial cells for the immediate establishment of a monolayer on a vascular graft at surgery. Surgery. 1986;100:392-9.

15. Kern PA, Knedler A, Eckel RH. Isolation and culture of microvascular endothelium from human adipose tissue. $J$ Clin Invest. 1983;71:1822-9.

16. Visser MJ, van Bockel JH, van Muijen GN, van Hinsbergh VW. Cells derived from omental fat tissue and used for seeding vascular prostheses are not endothelial in origin. A study on the origin of epitheloid cells derived from omentum. J Vasc Surg. 1991;13:373-81.

17. Karube N, Soma T, Noishiki Y, Yamazaki I, Kosuge T, Ichikawa Y, et al. Clinical long-term results of vascular prosthesis sealed with fragmented autologous adipose tissue. Artif Organs. 2001;25:218-22.

18. Noishiki Y, Tomizawa Y, Yamane Y, Okoshi T, Satoh S, Matsumoto A. Acceleration of neointima formation in vascular prostheses by transplantation of autologous venous tissue fragments. Application to small-diameter grafts. J Thorac Cardiovasc Surg. 1993;105:796-804.

19. Boyer M, Townsend LE, Vogel LM, Falk J, Reitz Vick D, Trevor KT, et al. Isolation of endothelial cells and their progenitor cells from human peripheral blood. J Vasc Surg. 2000;31:181-9.

20. Murohara T, Ikeda H, Duan J, Shintani S, Sasaki K, Eguchi H, et al. Transplanted cord blood-derived endothelial precursor cells augment postnatal neovascularization. J Clin Invest. 2000;105:1527-36.

21. Frazier OH, Baldwin RT, Eskin SG, Duncan JM. Immunochemical identification of human endothelial cells on the lining of a ventricular assist device. Tex Heart Inst J. 1993;20:78-82.

22. Shirota T, He HB, Yasui H, Matsuda T. Human endothelial progenitor cell (EPC)-seeded hybrid graft: proliferative and antithrombogenic potentials in vitro and fabrication processing. Tissue Eng. 2003;9:12736.

23. Matsuda T, Miwa H. A hybrid vascular model biomimicking the hierarchic structure of arterial wall. neointimal stability and neoarterial regeneration process under arterial circulation. J Thorac Cardiovasc Surg. 1995;110:988-97.

24. Tateishi E, Masaki H, Matsubara H. Clinical feasible therapeutic angiogenesis using autologous implantation of bone marrow-derived mononuclear cells to ischemic limbs [abstract]. Jpn Circ J. 2001; 65(suppl 1-A):181. 